\title{
PAPER
}

\section{“ KASUS PEMBUNUHAN SUAMI DAN ANAK TIRIDITINJAU DARI TEORI HATI NURANI DAN TINDAKAN MANUSIA “}

Disusun dalam memenuhi tugas mata kuliah Filsafat Manusia.

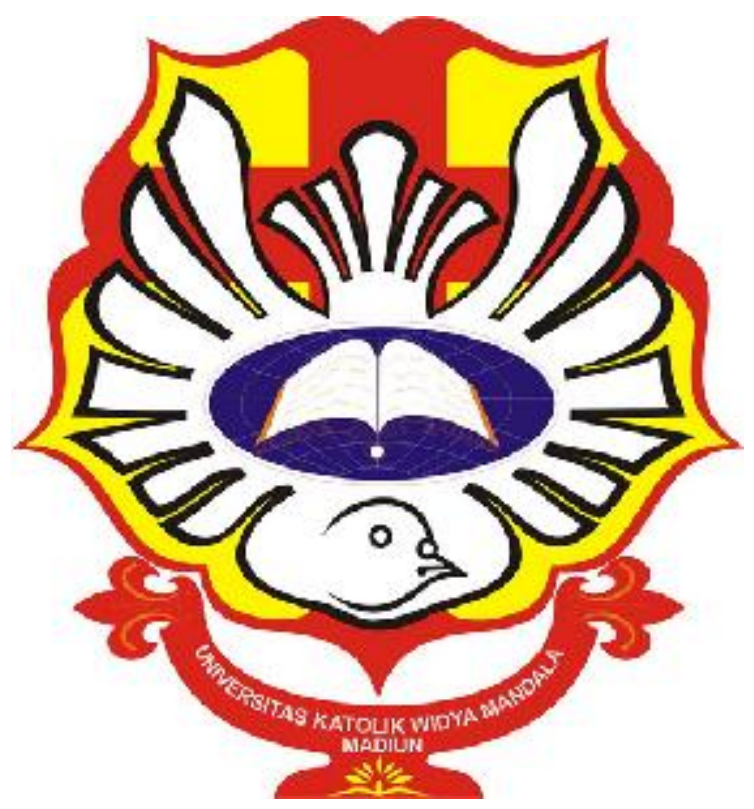

Disusun Oleh :

Margaretha Lia Pratiwi 3803019036

JURUSAN AKUNTANSI

FAKULAS EKONOMI DAN BISNIS

UNIVERSITAS KATOLIK WIDYA MANDALA SURABAYA KAMPUS MADIUN 


\begin{abstract}
ABSTRAK
Banyak sekali kasus pembunuhan yang terjadi di lingkup keluarga. Bahkan tak jarang yang menjadi korban adalah orang-orang yang disayangi. Pembunuhan di dalam keluarga sering terjadi karena motif ekonomi . Ekonomi keluarga yang pas-pasan namun gaya hidup yang tinggi membuat mereka gelap mata sehingga tega melakukan pembunuhan yang menyebabkan mereka harus mendekam dibalik jeruji penjara selama beberapa tahun. Membunuh merupakan tindakan kejahatan yang sangat fatal karena membunuh berarti sebuah tindakan merenggut nyawa orang lain. Tidak ada satu ajaran hukum maupun ajaran agama di Indonesia yang mengijinkan adanya tindakan pembunuhan. Tentunya kejahatan seperti ini sangat menyita perhatian kita sebagai warga Indonesia.
\end{abstract}

Keywords : Pembunuhan, Kejahatan, Keluarga 


\section{DAFTAR ISI}

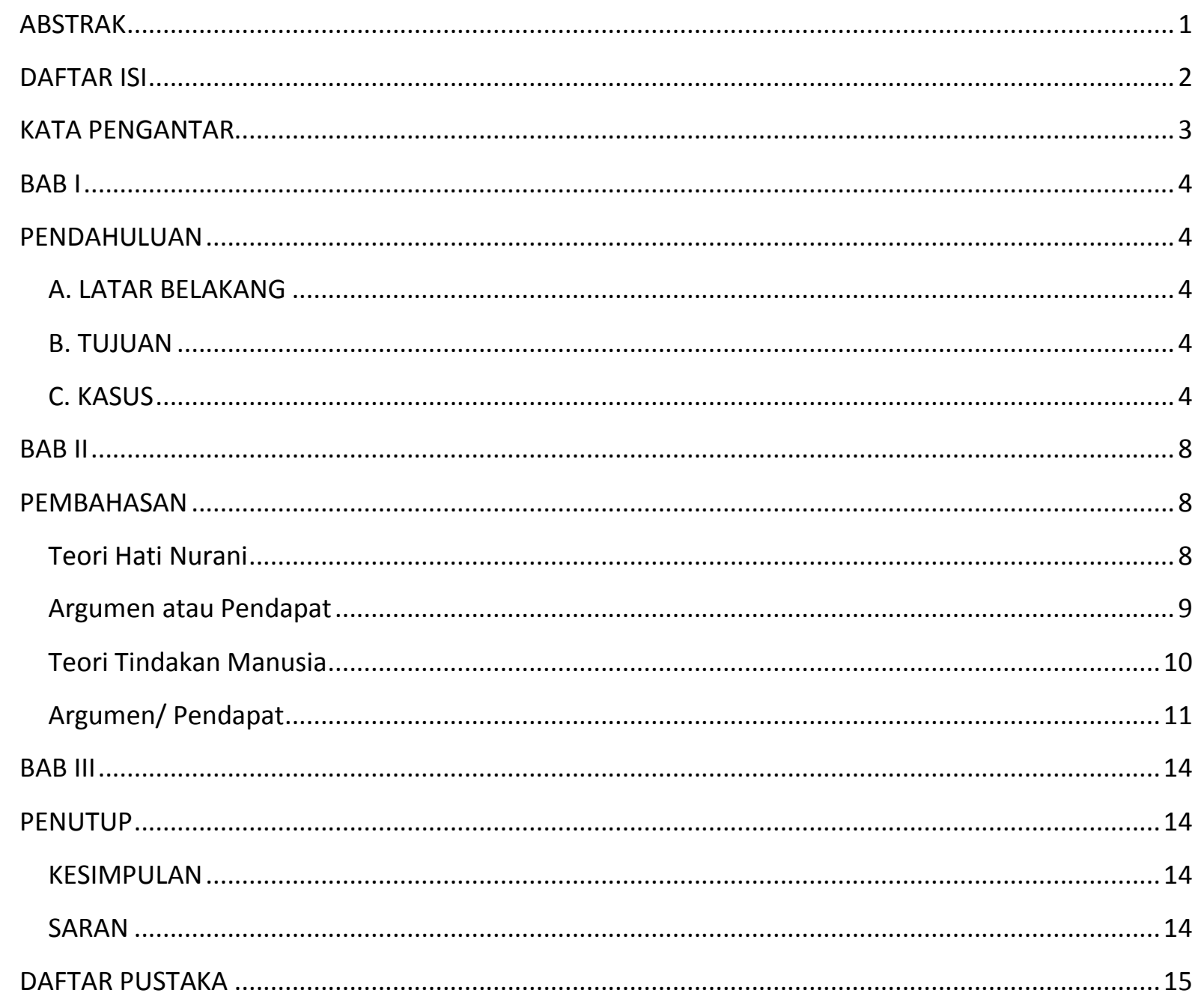




\section{KATA PENGANTAR}

Puji dan syukur saya ucapkan kepada Tuhan Yang Maha Esa karena atas berkat-Nya paper ini dapat terselesaikan dengan baik. Tidak lupa saya ucapkan terimakasih pula kepada phakpihak yang telah membantu saya dalam mnyelesaikan paper ini dengan baik.

Paper ini saya susun berdasarkan pengetahuan yang saya peroleh dari buku filsafat moral dan media elektronik dengan harapan dapat menambah pengetahuan para pembaca tentang kasus pembunuhan ditinjau dari teori hati nurani dan realitas kejahatan.

Akhirnya, saya menyadari bahwa penulisan paper ini masih jauh dari sempurna. Oleh karena itu, saya mengharapkan kritik dan saran yang sifatnya membangun untuk dapat menjadi pembelajaran bagi saya dalam menulis paper.

Madiun,30 November 2019

Penulis 


\section{BAB I}

\section{PENDAHULUAN}

\section{A. LATAR BELAKANG}

Pembunuhan merupakan suatu tindakan menghilangkan nyawa seseorang yang dilakukan oleh individu maupun beberapa orang. Pembunuhan merupakan salah satu tindakan yang melanggar hukum. Seseorang atau beberapa orang melalukan pembunuhan karena alasanalasan seperti asmara, kecemburuan sosial, ekonomi, politik, dendam dan lain sebagainya. Pelaku pembunuhan dapat seorang diri maupun kelompok, pembunuhan dapat terjadi secara sengaja atau direncanakan. Bahkan karena alasan alasan tersebut tak jarang pelaku pembunuhan berani dan tega membunuh keluarga maupun orang yang disayangnginya.

\section{B. TUJUAN}

Tujuan penulisan paper ini:

1. Untuk menganalisis kasus pembunuhan yang ditinjau dari teori hati nurani manusia.

2. Untuk menganalisis kasus pembunuhan yang ditinjau dari teori tindakan manusia

3. Untuk memenuhi tugas akhir filsafat manusia.

\section{KASUS}

Aulia Kesuma sedang bimbang. Pikirannya pusing terlilit utang di bank. Jumlahnya miliaran, Edi Chandra Purnama sebagai suami lebih terlihat tenang. Permintaan Aulia Kesuma agarn menjual rumah sering dijawab tidak mengenakkan. Bukan solusi yang datang, justru cacian dan makian. Bukan sekali Pupung, sapaan akrab Edi, memaki sang istri. Wanita berumur 45 tahun itu sudah kenyang mendengar cacian dari sang suami. Membuat Aulia sampai memendam dendam. Sampai satu titik dirasa kelewatan, lalu merencanakan pembunuhan.

Pada pertengahan Juli 2019, Aulia menghubungi dua mantan asisten rumah tangganya, Karsini dan suaminya,Rodi. Tujuan Aulia menghubungi kedua mantan asisten rumah tangganya adalah untuk mencarikan dukununtuk mengirimkan guna-guna kepada suaminya,namun usaha tersebut gagal bahkan utang semakin menumpuk. Keluhan utang Aulia Kesuma ditambah berat dengan keluhan anak tirinya yang bernama Muhammad Adi Prada alias Dana yang berumur 23 tahun. Danamerupakan anak kandung dari Pupung dan 
istri pertamanya, Aulia tidak sendiri, ia juga membawa anak kandung dari pernikahan pertamanya bernama Geovani Kelvin (25).

Pernikahan Pupung dan Aulia sudah berjalan sembilan bulan. Hubungan Dana dengan Aulia kerap bersitegang. Awalnya hubungan keduanya sangat baik. Namun, semuanya berubah ketika Aulia mengandung buah cintanya dengan Pupung. Hingga suatu waktu Dana mengirim pesan buat Aulia yang berisi ancaman bahwa Dana ingin membunuh istri kedua ayahnya itu. Dendam Aulia semakin menumpuk. Kemudian Aulia meminta Rodi untuk mencari pembunuh bayaran dengan upah Rp 500 juta dijanjikan. Tiga orang pekerja serabutan asal Lampung Timur segera didatangkan. Aulia meminta kriteria calon pembunuh suaminya harus berani,tidak asal-asalan,karena Pupung suami Aulia dikenal jago silat.

Tiga orang datang ke Jakarta,mereka adalah Agus, Sugeng, dan Alpa. Rodi juga ikut dalam rombongan. Mereka diantar Karsini pada Jumat,23 Agustus 2019. Aulia menyewakan sebuah penginapan di wilayah Pasar Minggu, Jakarta Selatan. Setelah mereka tiba di Jakarta mereka langsung menemui Aulia di apartemen kawasan Kalibata. Strategi pembunuhan dimatangkan. Awalnya mereka ingin Pupung dan Dana ditembak hingga seolah terjadi perampokan. Senjata telah disiapkan, namun ditengah pembahasan rencana urung dilakukan. Wanita itu ingin memakai cara lain.

Tiga puluh butir obat tidur ternyata sudah disiapkan oleh Aulia. Obat itu digerus kemudian ditaburkan di jus tomat kesukaan keluarga setelah membelinya sekitar Kalibata. Sebagai seorang ibu, Aulia sudah paham betul karakter tiap penghuni rumah. Dalam pembahasan rencana Aulia dimatangkan. Dari Kalibata, mereka kemudian menuju rumah Aulia diana Pupung dan Dana berada yaitu di jalan Lebak Bulus I Kavling 29 Blok B/U Nomor 15 RT 03 RW 05,Lebak Bulus, Jakarta Selatan.

Aulia Kesuma tiba di rumah ketika langit sudah gelap.Turun dari mobil menenteng dua bungkus jus tomat. Sedangkan Agus dan Sugeng disembunyikan Aulia di garasi menunggu kode sampai calon korban benar-benar terlelap. Kemudian segera Pupung dan Dana disekap dengan menggunakan kain disiram alkohol tinggi.Pupung kebetulan sedang bersantai menonton televisi. Aulia langsung menyerahkan tanpa basa-basi. Kemudian satu bungkus lagi disimpan dalam kulkas untuk sang anak tiri, Dana.

Jus tomat berisi gerusan obat diminum Pupung. Sempat ada sedikit protes dari sang suami. Rasa minuman di genggaman agak pahit. Ucapan dibalas Aulia, "Dicampur sayuran 
sedikit." Jawab Aulia tidak terlalu dipedulikan. Pupung tetap menghabiskan minuman.Keduanya sempat berbincang santai. Aulia mulai berubah manja. Merayu, mengajak Pupung menuju ranjang kamar. Sekitar pukul 21.30 WIB, efek obat tidur belum kentara.Kemudian, wanita itu mengajak suaminya bercinta dengan harapan Pupung semakin lelah, lalu cepat tertidur. Namun rupanya perhitungan Aulia tidak sesuai, Pupung masih tersadar dan sempat melakukan senam.

Di ujung ranjang, Aulia mengintip pura-pura tertidur sembari memantau gerak-gerik Pupung. Tak lama, sang suami ke ranjang dan tertidur nyenyak. Wanita itu bangun dan memastikan Pupung benar-benar tertidur. Ia kemudian bergegas menghampiri Agus dan Sugeng di garasi.Usai memberi kode, keduanya menuju kamar. Atas perintah Aulia, keduanya membekap Pupung memakai kain handuk beraroma alkohol.Dalam keadaan lemas, Pupung tidak bisa melawan. Kemampuan silat Cimande tak bisa dikeluarkan. Badannya ditekan dua orang. Para pembunuh tak sedikit pun memberi kesempatan korbannya melawan hingga nyawa Pupung akhirnya melayang.Korban pertama kemudian disembunyikan di dalam sebuah ruangan lantai dua, sambil menunggu korban selanjutnya.

Kebetulan malam itu Dana belum pulang. Justru Kelvin terlebih dulu hadir usai pembunuhan. Sang ibu kemudian memintanya untuk membunuh adik tirinya. Permintaan disetujui. Kelvin menuruti permintaan ibu kandungnya. "Kalau memang tugasku melumpuhkan Dana. Karena kan enggak ada yang bisa akrab," alasan itu menjadi pintu masuk. Memang selama ini Kelvin merasa kesal dengan ayah tirinya. Ditambah perlakukan Dana kepada Aulia dan juga adik kandungnya Angle.Kelvin dan Angle merupakan anak dari suami pertama Aulia. Mereka tinggal di bilangan Kalideres karena menolak hidup bersama dengan Pupung dan Dana.

Sebagai kakak, amarah Kelvin sebenarnya sudah memuncak. Apalagi mengetahui adiknya disebut pelacur oleh Dana. Semua pengalaman pahit membuat Kelvin dendam kesumat. Tanpa pikir panjang menuruti permintaan membunuh Dana. Sabtu, 24 Agustus 2019 sekitar pukul 02.00 WIB, suara motor terdengar. Tanda Dana sudah pulang. Tanpa rasa curiga, dia membuka kulkas dan meminum jus tomat yang dibeli ibu tiri.Sambil meminum jus, Dana masuk kamar. Tak lama Kelvin datang menghampiri. Dua anak muda itu berbincang sambil main game.Perlahan Dana tampak kelelahan, rasa kantuknya tak bisa ditahan. Hingga akhirnya Dana lelap tertidur. Jelang subuh, aksi pembunuhan dimulai. Kali 
ini Kelvin langsung menjadi eksekutor.Kelvin, Agus dan Sugeng, mengendap-endap masuk ke kamar Dana. Dua orang Lampung Timur itu memegang erat tubuh korban.

Cara pembunuhan persis seperti diterapkan kepada Pupung. Kelvin membekap kain handuk berbau alkohol menyengat ke arah muka. Sampai akhirnya Dana tewas di tangan kakak tirinya. Lalu mereka merencanakan seakan rumah terbakar lalu mereka meletakkan mmaat keduna di dalam mobil lalu mobil juga ikut terbakar dan akhirnya mayat mereka pun ditemukan. 


\section{BAB II}

\section{PEMBAHASAN}

\section{Teori Hati Nurani}

Hati nurani ialah hati yang mengetahui. Sebenarnya proposisi " hati yang mengetahui"samasekalitidaktepat. Soal pengetahuan tak pernah merupakan soal hati, melainkan soal akal budi ( rasio). Dan sebab itu, jika dikatakan hati nurani mengetahui, maksudnya ialah hati kita memiliki semacam pertimbangan yang membimbing kehendak kita.Pengetahuan hati sering kali lebih merupakan pengetahuan yang dicurahkan, dipatrikan, ditancapkan dalam hati kita. Karena hati kita tidak bisa berpikir ( hanya akal budi saja yang bisa berpikir), hati nurani sering kali disebut sebagai " suara Allah". Lalu bagaimana dengan mereka yang tidak beragama / tidak mengenal Tuhan? Apakah mereka mempunyai hati nurani juga?.

Meskipun tidak mengenal Tuhan dan sabda-sabda- Nya, manusia dapat melanggar perintah Tuhan karena dengan hati nuraninya Tuhan hadir di dalam diri mereka. Tidak ada alasan bagi manusia yang tidak mengenal Allah untuk bertindak sekenannya, sebab mereka memiliki hati nurani yang dapat membimbing perbuatan mereka.Fenomen hati nurani merupakan fenomen pertimbangan boleh/ tidak boleh atau baik / buruk tentang segala sesuatu yang dilakukan oleh manusia.Hati nurani sepertinya mengajukan paradigma nilai- nilai moral yang bersumber dari Tuhan sendiri.

Macam-macam hati nurani :

- Hati nurani sesat

Hati nurani sesat menjadikan segala yang baik menjadi buruk dan yang buruk menjadi baik.

- Hati nurani bimbang

Hati nurani bimbang berarti pengetahuannya tidak pasti.Hati nurani tidak pernah bimbang, karena jika bimbang orang tidak memiliki pengetahuan moralitas dari tindakannya.

- Hati nurani tumpul

Hati semacam ini kurang peka pada nilai-nilai kebenaran sehingga lama-kelamaan kesetiaanya pada nurani menjadi tumpul. 
- Hati nurani skrupel

Orang- orang yang memiliki hati nurani skrupel dihantui oleh perasaan untuk tidak berdosa dalam hal yang sekecil-kecilnya secara ekstrem ( skrupel).

- Hati nurani tajam

Hati nurani semacam ini terlatih untuk dengan cepat membedakan mana yang baik dan mana yang buruk.

\section{Argumen atau Pendapat}

Berdasarkan teori di atas Aulia Kesuma memiliki hati nurani sesat. Aulia Kesuma menurut saya memiliki hati nurani yang sesat karena ia menghalalkan berbagai cara untuk membunuh suami dan anak tirinya. Alasan Aulia membunuh suami dan anak tirinya adalah masalah utang yang melilit keluarganya ditambah sang suami yang tidak mau berpikir atau mencari solusi untuk melunasi utang mereka yang jumlahnya hingga miliaran. Aulia Kesuma tidak memikirkan akibat dari perbuatannya, ia hanya berpikir bahwa dengan kematian suami dan anak tirinya dapat menyelesaikan masalah namun semua itu salah karena setelah membunuh suami dan anak tirinya, Aulia malah harus mendekam di penjara. Aulia begitu dalam memendam dendam sehingga Aulia menganggap bahwa dengan membunuh suami dan anaknya akan meringankan beban dan tentunya Aulia dapat menjual rumah untuk membayar utang.

Aulia tidak memikirkan efek dari semua itu karena Aulia hanya memikirkan dendam dan bagaimana cara agar ia dapat menjual rumah untuk melunasi utang di bank yang jumlahnya hingga miliaran. Bahkan Aulia tidak hanya membunuh suami dan anak tirinya namun juga membakar mayat mereka di dalam mobil yang sengaja di bakar.Harusnya Aulia tidak melakukan hal itu, karena dengan melakukan itu Aulia harus mendekam di penjara.Hati nurani sesat sangat berbahaya karena orang yang berada dalam hati nurani sesat akan melakukan segala cara yang menuut orang itu baik padahal tindakan itu salah dan akan merugikan diri sendiri dan orang lain.

Disaat seseorang mengalami kegundahan atau hati nurani berada dalam kesesatan di harapkaan orang itu tiidak melakukan banyak hal yang dapat membahayakan orang lain maupun diri sendiri. Saat menghadapi banyak masalah orang yang memilikihati nurani sesat akan melakukan tindakan yang sangat berbahaya. Seperti Aulia karena ia memiliki hati nurani yang telah sesat maka ia rela membunuh suami dan anak tirinya yang nerupakan 
keluarganya.Hati nurani Aulia telah tertutup oleh dendam dan akhirnya menjadi hati nurani yang sesat sehingga ia tega membunuh suami dan anak tirinya. Masalah ekonomi menjadi pemacu adanya kasus pembunuhan ini.

Seharusnya hati nurani dapat membimbing orang dalam bertindak namun dalam kasus ini hati nurani yang telah tertutup oleh dendam menjadi sesat dan membuat Aulia merencanakan pembunuhan. Setiap tindakan yang dilakukan oleh orang yang memiliki hati nurani sesat akan mengaah kepada kejahatan yang tidak dapat di pertanggungjawabkan. Memang orang yang memilik hati nurani sesat tidak dapat menutup mata atas apa yang telah mereka perbuat, maka orang yang berada dalam hati nurani sesat harus keluar dari kesesatannya agar ia tidak melakukan perbuatan yang mengarah pada kejahatan yang tidak dapat di pertanggungjawabkan. Atas perbuatannya Aulia pun dapat disebut sebagai orang yang tidak memiliki hati nurani.

Hati nurani sesat harus di latih agar menjadi hati nuarani yang tajam sehingga orang yang memiliki hati nurani sesat tidak akan melakukan hal-hal yang tidak benar. Sangat disayangkan apabila yang menjadi korban dari tindakan yang dilakukan karena hati nurani sesat yang menutupi mata mereka sehingga keluarga sendiri pun menjadi korba apalagi karaena dendam yang menyebabkan tindakan mereka tidak terkendali.

\section{Teori Tindakan Manusia}

Bertindak adalah ciri khas setiap makhluk hidup. Tindakan manusia adalah pencetusan dirinya. Menurut Maurice Blondel tindakan manusia adalah representasi dirinya yang paling umum. Selain yang paling umum, tindakan manusia juga merupakan representasi dirinya yang paling lengkap. Dengan tindakannya, manusia menghadirkan dirinya secara memesonakan. Lebih lanjut Blondel menulis “ Tindakan adalah fakta yang paling meneyeluruh sekaligus konstan dalam hidupku”, Blondel menyakinkan perihal siapa dirinya.

Jika manusia hendak mengomunikasikan diri kepada kepada sesamanya,Tuhannnya atau siapapun, dia pasti merealisasikannya dalam tindakan. Hampir tidak ditemukan sarana lain untuk itu selain tindakan. Tindakan manusia dibedakan dalam actus hominis dan actus humanus. Dalam actus hominis, tindakan manusia tampil sebagai suatu gerakan belaka. Dalam tindakan itu manusia berada pada level yang paling rendah. Tindakan manusia disebut human action ( actus humanus) apabila, eksitensinyasebagai makhluk rasional tercetus secara 
menyakinkan. Dalam actus humanustindakan manusia dikenal syarat tindakan yaitu tahubebas-mau.

Tindakan manusia juga dibedakan menjadi dua yaitu tindakan baik dan tindakan buruk. Tindakan baik adalah tindakan yang dilakukan dengan tahu,mau, dan bebas yang selaras dengan nilai-nilai kebaikan. Tindakan buruk adalah tindakan yang dilakukan menyimpang dari nilai-nilai kebaikan yang dilakukan dengan tahu-mau-bebas. Didalam struktur tindakan manusia ada directly voluntary dan indirectly voluntary. Dalam directly voluntarykeputusan tindakan maupun konsekuensi-konsekuensi yang menyertai dari keputusan tersebut milik pelaku sendiri.

\section{Argumen/ Pendapat}

Tindakan yang dilakukan Aulia Kesuma merupakan tindakan yang termasuk tindakan buruk karena ia membunuh suami dan anak tirinya. Tindakan membunuh adalah tindakan yang sangat buruk. Membunuh adalah tindakan yang sangat dilarang oleh agama dan hukum. Dalam kasus ini tindaakan yang dialkukan oleh Aulia Kesuma sangat kejam karena ia berani menghilangkan nyawa suami dan anak tirinya.Tindakan Aulia kesuma masuk dalam struktur tindakan yang directly voluntary karena tindakan membunuh merupakan tindakan yang disebabkan pelaku. Dalam kasus ini pembunuhan telah direncanakan oleh Aulia Kesuma karena ia telah menyimpan dendam.

Tindakan Aulia Kesuma yang awalnya hanya dendam, namun karena dendam itu berakhir dengan pembunuhan. Tindakan membunuh adalah tindakan yang buruk karena menyimpang dari nilai-nilai kebaikan. Tentu dengan adanya tindakan ini Aulia Kesuma dan anak buahnya serta anak kandungnya harus dihukum karena mereka telah menghilangkan nyawa dua orang sekaligus dan tidak menguburkan mayatnya secara wajar, namun mayat keduanya dibakar didalam mobil.

Sungguh kejam tindakan Aulia, padahal ia seorang ibu namun ia tega membunuh anggota keluarganya hanya karena dendam. Alasan-alasan sepele kerap menjadi penyebab dari kasus pembunuhan. Ekonomi,kecemburuan,KDRT,atau karena iri hati dan lain sebagainya menjadi motif dari pembunuhan yang bahkan korbannya adalah keluarganya sendiri. Dalam kasus ini yang menjadi alasan Aulia untuk membunuh suami dan anak tirinya adalah ekonomi.

Hutang yang menumpuk hingga miliaran yang tak kunjung terluansi dan usaha yang gagal menjadi pemicu tindakan Aulia Kesuma. Sang suami yang yang menolak menjual rumah 
untuk melunasi utang hingga sang suami yang tidak mau mencari cara untuk melunasi hutang tersebut ditambah dengan sikap dari anak tirinya yang mengancam akan membunuh Aulia membuaat Aulia menyimpan dendam. Masalh yang seharusnya bisa diselesaikan secara kekeluargaan namun akhirnya diselesaikan dengan cara yang keji dan adanya korban yang merupakan anggota keluarga.

Tindakan seseorang dapat dikatakan baik dan buruk dilihat dari efek atau akibat dari tindakan yang diperbuat orang itu. Seharusnya Aulia tidak membunuh suami dan anak tirinya. Aulia melakukan tindakan yang seharusnya tidak dilakukan yaitu menghilangkan nyawa suami dan anak tirinya. Tindakan buruk merupakan tindakan yang dilakukan menyimpang dari nilai-nilai kebaikan dan dilakukan dengan melanggar tahu- mau- bebas.

Keluarga harusnya menjadi tempat yang tepat untuk menyelesaikan masalah bukan malah menjadi korban dari penyelesaian masalah sehingga korbannya adalah keluarga sendiri. Aulia melakukan tindakan yang sangat buruk dan mengakibatkan efek yang sangat berkepanjangan bagi dirinya sendiri yaitu ia harus mendekam di penjara. Masalah tidak harus diselesaikan dengan kekerasan yang menyebabkan banyak korban. Dalam menyelesaikan masalah harusnya hati kita tidak bimbang dan kita harus dalam keadaan yang siap untuk menyelesaikan masalah dan tidak ada dendam ataupun kekesalan sehingga masalah dapat diselesaikan dengan baik.

Tindakan buruk sangat dibenci oleh masyarakat karena akibat dari tindakanburuk adalah hal yang sangat merugikan. Tindakan yang dilakukan oleh Aulia mengakibatkan ia dijerat pasal 340 KUHP. Tindakan yang dilakukan oleh seseorang atau sekelompok orang yang mengakibatkan orang yang melakukan tindakan itu dijerat pasal-pasal UUD pasti tindakan itu buruk dan salah. Tindakan yang buruk membuat orang yang melakukannya harus menanggung resiko. Banyak resiko yang harus ditanggung pelaku karena tindakan buruknya seperti: dikucilkan oleh masyarakat, mendekam di penjara, dihantui rasa berdosa dan bersalah dan resiko lainnya.

Aulia Kesuma pun merasakan resiko dari tindakan buruk yang ia lakukan. Resiko yang dirasakan oleh Aulia adalah ia harus mendekam di penjara. Banyak orang melakukan tindak kejahatan tanpa memandang siapa yang akan menjadi korban dari tindakannya tersebut. Kejahatan seringkali dianggap sebagai tindakan yang lazim untuk dilakukan. Padahal tindak kejahatan merupakan tindakan yang buruk. Pembunuhan juga termasuk tindak kejahatan 
yang sangat fatal dansangatberatdampaknya. Sehingga pembunuhan sangat dilarang dan termasuk dalam tindak kejahatan. Pembunuhan dilarang karena dengan adanya pembunuhan maka ada korban jiwa yang menjadi korban dari pembunuhan.

Tindakan yang seharusnya tidak dilakukan malah dilakukan oleh Aulia Kesuma sehingga ia harus menanggung resiko dari tindakan yang ia perbuat. Keluarga yang seharusnya bisa menjadi tempat untuk menyelesaikan masalah secara kekeluargaan malah harus menjadi korban dari penyelesaian masalah yang dilakukan secara kekerasan. Aulia tidak memikirkan nasib suami dan anak tirinya yang menjadi korban dari tindakannya. Sehingga Aulia melakukan pembunuhan tanpa memandang suami dan anak tirinya yang menjadi korban bahkan tindak kejahatan itu telah direncanakan oleh Aulia dan anak kandungnya serta anak buahnya.

Pembunuhan yag dilakukan oleh Aulia merupakan tindakan yang sangat salah karena membunuh merupakan tindakan yang sangat dibenci oleh masyarakat. Sehingga Aulia menerima hukuman yaitu harus mendekam di penjara. Akibat dari tindakannya Aulia harus menanggung semua derita itu. Sehingga Aulia tidak dapat merasakan hidup tenang walaupun suami dan anak tirinya telah terbunuh. Tindakan yang dialakukan oleh Aulia sangat buruk dan tidak bermoral karena ia tega membunuh anggota keluarganya sendiri yaitu suami dan anak tirinya sendiri. Sikap dan tindakan Aulia dalam menyelesaikan masalah harus dihindari agar tidak terjadi hal yang terdapat seperti kasus diatas.

Tindakan buruk tidak boleh dilakukan dalam situasi apa pun karena dengan adanya tindakan buruk maka terjadi hal-hal seperti kasus di atas yang nantinya akan merugikan diri sendiri maupun orang lain. Sebaiknya dalam menyelesaikan masalah harus dengan kepala yang dingin sehingga tidak akan ada kejahatan yang terjadi. Masalh dapat diselesaikan dengan berbagai cara namun tidak dengan tindak kejahatan seperti pembunuhan mapn ang lainnya. Selesaikan masalah dengan cara kekeluargaan apabila masalah bersifat kekeluargaan atau diselesaikan melalui jalur hukum. 


\section{BAB III}

\section{PENUTUP}

\section{KESIMPULAN}

Dari kasus diatas dapat disimpulkan bahwa ditinjau dari teori hati nurani maka Aulia termasuk dalam hati nurani sesat dan ditinjau dari teori tindakan manusia maka tindakan Aulia termasuk dalam tindakan yang buruk.

\section{SARAN}

Seharusnya Aulia tidak membunuh suami dan anak tirinya lalu membakar mayatnya di mobil karena akibat dari tindakannya Aulia harus mendekam di penjara. 


\section{DAFTAR PUSTAKA}

- Giovani, V., \& Dewantara, A. (2018). ANALISIS KASUS TEROR BOM SURABAYA DAN SIDOARJO DITINJAU DARI SUDUT PANDANG HATI NURANI YANG SESAT.

- Dewantara, A. (2017). Filsafat Moral (Pergumulan Etis Keseharian Hidup Manusia).

- Dewantara, A. KASUS MEMILUKAN SEORANG BOCAH DI GOWA TEWAS DI TANGAN AYAH KANDUNG DITINJAU DARI TEORI PRINSIP REFLEKSI HATI NURANI MANUSIA.

- Jonathan, R. R., \& Dewantara, A. (2018). KASUS MENINGGALNYA RICKO ANDREAN MAULANA SUPORTER BOBOTOH DITINJAU DARI HATI NURANI DAN MORAL KEUTAMAAN.

- Violytha, F. M., \& Dewantara, A. (2018). KASUS PEMBUNUHAN SATU KELUARGA DI DELI SERDANG DITINJAU DARI TINDAKAN MANUSIA (ACTUS HUMANUS) DAN TATANAN MORAL SUBJEKTIF (HATI NURANI SESAT).

- Wantites, S. A., \& Dewantara, A. (2018). KASUS PEMBUNUHAN ABDULLAH FITHRI SETIAWAN (DUFI) DITINJAU DARI TEORI STRUKTUR TINDAKAN MANUSIA DAN TATANAN MORAL SUBJEKTIF.

- Aprillia, R., \& Dewantara, A. (2018). STUDI KASUS PEMBUNUHAN BAYI YANG DILAKUKAN OLEH AYAH KANDUNG DARI TEORI TINDAKAN MANUSIA DAN REALITAS KEJAHATAN.

- Rahayu, A., \& Dewantara, A. (2018). STUDI KASUS EKSEKUSI MATI TKI INDONESIA (TUTI TURSILAWATI) DITINJAU DARI TEORI TINDAKAN MANUSIA, TATANAN MORAL SUBJEKTIF, DAN TATANAN MORAL OBJEKTIF. 
